\title{
Pengaruh Budaya Pengelolaan dan Tujuan Terhadap Komitmen Organisasi Pada UPTD di Cirebon
}

\author{
Rhestina Atika Dwiyanti \\ Universitas Swadaya Gunung Jati \\ rhestinatika@gmail.com \\ Edy Hartono \\ Universitas Swadaya Gunung Jati \\ Sandi Nasrudin Wibowo \\ Universitas Swadaya Gunung Jati \\ sandi.nwibowo@ugj.ac.id
}

\begin{abstract}
Abstrak Penelitian ini bertujuan untuk mengetahui pengaruh budaya organisasi dan kepuasan kerja secara parsial maupun simultan terhadap komitmen organisasi pada UPTD Wilayah Pelayanan Pengelolaan Jalan dan Jembatan VI. Populasi dalam penelitian ini adalah UPTD Jasa Pengelolaan Jalan dan Jembatan Wilayah VI. Teknik pengambilan sampel dalam penelitian ini adalah sampel jenuh, yaitu teknik pengambilan sampel bila semua anggota populasi dijadikan sampel. Sampel yang diambil dalam penelitian ini sebanyak 79 responden. Metode dalam pengumpulan data ini menggunakan kuesioner, sedangkan metode dalam penelitian ini menggunakan analisis regresi linier berganda. Hasil penelitian ini menunjukkan bahwa budaya organisasi berpengaruh signifikan terhadap komitmen organisasi dilihat dari > yaitu $9,502>1,664$ dan nilai (sig) $0,000<$ $0,05, t_{\text {hituna }} t_{\text {tabel }} t_{\text {hituna }} t_{\text {tabel }}$
\end{abstract}

Kata kunci Budaya Organisasi, Kepuasan Kerja dan Komitmen Organisasi

\section{PENDAHULUAN}

Komitmen organisasi mencerminkan sejauh mana seorang individu mengidentifikasi dengan organisasi dan berkomitmen untuk tujuannya. Komitmen organisasi berkaitan dengan tingkat keterlibatan orang-orang dengan organisasi tempat mereka bekerja dan tertarik untuk tinggal di organisasi. Karena untuk mencapai tujuan organisasi diperlukan suatu kerjasama agar tujuan organisasi tercapai. Keberhasilan dalam organisasi sangat ditentukan oleh keberhasilan dalam mengelola komitmen sumber daya manusia. Dengan demikian, suatu organisasi yang menunjukkan rasa kepedulian terhadap sumber daya manusianya dan menjadi tempat terbaik untuk bekerja akan mengakibatkan keterikatan pada organisasi tersebut dan merasa enggan untuk meninggalkannya. dirinya dengan organisasi dan berkomitmen pada tujuannya. Komitmen organisasi berkaitan dengan tingkat keterlibatan orang-orang dengan organisasi tempat mereka bekerja dan tertarik untuk tinggal di organisasi. Karena untuk mencapai tujuan organisasi diperlukan suatu kerjasama agar tujuan organisasi tercapai. Keberhasilan dalam organisasi ditentukan oleh keberhasilan dalam mengelola komitmen sumber daya manusia. Dengan demikian, 
suatu organisasi yang menunjukkan rasa kepedulian terhadap sumber daya manusianya dan menjadi tempat terbaik untuk bekerja akan mengakibatkan keterikatan pada organisasi tersebut dan merasa enggan untuk meninggalkannya. Keberhasilan dalam organisasi ditentukan oleh keberhasilan dalam mengelola komitmen sumber daya manusia. Dengan demikian, suatu organisasi yang menunjukkan rasa kepedulian terhadap sumber daya manusianya dan menjadi tempat terbaik untuk bekerja akan mengakibatkan keterikatan pada organisasi tersebut dan merasa enggan untuk meninggalkannya. Keberhasilan dalam organisasi ditentukan oleh keberhasilan dalam mengelola komitmen sumber daya manusia. Dengan demikian, suatu organisasi yang menunjukkan rasa kepedulian terhadap sumber daya manusianya dan menjadi tempat terbaik untuk bekerja akan mengakibatkan keterikatan pada organisasi tersebut dan merasa enggan untuk meninggalkannya. Budaya organisasi memiliki kekuatan untuk mengarahkan karyawan mencapai tujuan organisasi. Membangun budaya organisasi bukanlah hal yang mudah atau hanya seperti membalikkan tangan, tetapi merupakan hal yang sangat sulit. Sehingga perlu adanya sosialisasi agar ada kesadaran untuk menjalankan SOP agar SOP menjadi kebiasaan untuk menjalankan norma yang berlaku. Dengan kata lain, budaya organisasi dapat tumbuh dan berkembang di dalam organisasi karena diciptakan, diorganisir, dilaksanakan, dan dikembangkan oleh seluruh anggota organisasi yang dilakukan secara bersama-sama dalam suatu organisasi. Kepuasan kerja seseorang pada dasarnya menyangkut perilaku seseorang dalam bekerja pada suatu perusahaan, ia akan merasa nyaman dan memiliki loyalitas yang tinggi terhadap perusahaan apabila dalam pekerjaannya mendapatkan kepuasan kerja sesuai dengan yang diinginkannya. Kepuasan kerja dapat meningkatkan komitmen organisasi dalam perusahaan. Kepuasan kerja merupakan faktor penting yang menentukan keberhasilan suatu organisasi dan membantu organisasi untuk mencapai tujuannya. Karyawan yang puas cenderung lebih loyal kepada organisasinya dan juga pasti akan memelihara sifat positif dalam diri mereka terhadap pekerjaannya, oleh karena itu tidak mungkin mereka berpindah pekerjaan dan menganggap pekerjaannya lebih baik dari pekerjaan sebelumnya.

\section{LANDASAN TEORI}

\section{Budaya organisasi}

Budaya Organisasi oleh Nimran yang dijadikan acuan oleh Fauzi (2006) mendefinisikan budaya organisasi sebagai suatu sistem makna yang dimiliki bersama oleh suatu organisasi yang membedakannya dengan organisasi lainnya. Sistem makna telah dimiliki bersama dan diyakini oleh seluruh anggota organisasi, sehingga keseluruhan sistem makna mampu membedakan organisasi yang satu dengan yang lainnya. Menurut Robbins (2001) dalam (Busro, 2018) mendefinisikan budaya organisasi sebagai berikut: Budaya organisasi adalah sistem nilai yang diperoleh dan studi budaya organisasi pada sistem makna bersama yang dianut oleh organisasi dan pola kebiasaan dan anggota dasar yang membedakan organisasi dari organisasi. filosofi pendirinya, yang dibentuk menjadi aturan-aturan yang membentuk organisasi. Elemen berdasarkan pendapat Wallach (1983) dalam (Al-sada, 2017) birokrasi, inovatif, supportif. Dimensi budaya organisasi menurut (Edison et al., 2018) yaitu : Kesadaran diri, keagreifan, kepribadian, performa, dan orientasi tim.

\section{Kepuasan kerja}

Kepuasan Kerja Menurut Siqueira (2008), kepuasan kerja berarti mengevaluasi seberapa besar manfaat yang ditawarkan perusahaan dalam gaji dan promosi memuaskan 
individu, seberapa nyaman dia dengan rekan kerja dan atasan, dan seberapa banyak tugas yang diberikan kepada karyawan membuat dia senang dan merasa senang. . Menurut Siagian (Siagian, 2006) mendefinisikan sebagai berikut Kepuasan kerja adalah cara pandang seseorang, baik positif maupun negatif tentang pekerjaannya. Banyak faktor yang perlu diperhatikan dalam menganalisis kepuasan kerja seseorang. Jika dalam pekerjaannya seseorang memiliki otonomi atau tindakan, ada variasi, memberikan kontribusi penting bagi keberhasilan organisasi dan karyawan mendapatkan umpan balik tentang hasil pekerjaan yang mereka lakukan,

\section{Komitmen Organisasional}

Komitmen Organisasi menurut Steers dalam (Yuwalliatin, 2006) mendefinisikan komitmen organisasi sebagai rasa identifikasi, keterlibatan, dan loyalitas yang diungkapkan oleh seorang karyawan terhadap organisasinya. Rasa identifikasi, keterlibatan, dan loyalitas yang ditunjukkan oleh karyawan kepada atasannya tidak dapat dibuat-buat atau dibungkus dengan kata-kata seolah-olah, tetapi akan dengan sendirinya, siapa saja antara karyawan yang loyal dan karyawan yang tidak loyal dilihat dari keseriusan dalam bekerja, dan hasil yang diperoleh pertunjukan. Menurut Colquitt, LePine, dan Wesson (2011: 69) dalam (Wibowo, 2019) mendefinisikan komitmen organisasi sebagai berikut: Komitmen organisasi adalah keinginan beberapa pekerja untuk tetap menjadi anggota organisasi. (Kaswan, 2015) menjelaskan ada beberapa sifat dasar komitmen yaitu : Komitmen dimulai di dalam hati, Komitmen diuji oleh tindakan, Komitmen membuka menuju pintu pencapaian.

\section{METODOLOGI PENELITIAN}

Penelitian ini menjadikan seluruh objek atau populasi yang ada di UPTD Wilayah Pelayanan Pengelolaan Jalan dan Jembatan VI Cirebon untuk diteliti. Sampel dalam penelitian ini menggunakan metode Non-Probability Sampling atau tidak memberi peluang sama bagi setiap anggota populasi untuk dipilih menjadi sampel (Sugiyono, 2017) dengan tipe Saturated Sampling. Sampel dalam penelitian ini adalah pegawai UPTD Jasa Pengelolaan Jalan dan Jembatan Area VI yang berjumlah 79 pegawai. Maka dalam penelitian ini peneliti menjadikan seluruh karyawan responden untuk dijadikan sampel dalam penelitian.

\section{HASIL PENELITIAN}

Berdasarkan hasil Adjust R Square (R2) dari tabel model ringkasan sebesar 0,678 atau $67,8 \%$ yang berarti variabel budaya organisasi dan kepuasan kerja terhadap komitmen organisasi mampu menjelaskan 67,8\% dan sisanya 32,2\% dipengaruhi oleh faktor lain.

Tabel 1.1 Koefisien Determinasi Variabel Budaya Organisasi (X1) dan Kepuasan Kerja (X2)

\begin{tabular}{|c|c|c|c|c|}
\hline \multicolumn{5}{|c|}{ Ringkasan Model } \\
\hline Model & $\mathrm{R}$ & Kotak R & $\begin{array}{c}\text { Disesuaikan R } \\
\text { Square }\end{array}$ & $\begin{array}{c}\text { Std. } \\
\text { Kesalahan } \\
\text { Perkiraan }\end{array}$ \\
\hline 1 & ,829a &, 687 &, 678 & 3.710 \\
\hline
\end{tabular}


Koefisien determinasi adalah mengukur seberapa jauh kemampuan model dalam menerangkan variasi variebel dependen (Ghozali, 2016). Analisis regresi berganda dilakukan untuk mengetahui besarnya pengaruh beberapa variabel bebas secara bersama-sama terhadap variabel terikat, dalam penelitian ini variabel Budaya Organisasi (X1) dan Kepuasan Kerja (X2) secara bersama-sama terhadap Komitmen Organisasi (Y). Berikut adalah hasil analisis regresi berganda dengan menggunakan SPSS versi 25.00 for windows.

Tabel 1.2 Hasil Analisis Regresi Berganda

\begin{tabular}{|c|c|c|c|c|c|c|}
\hline \multicolumn{7}{|c|}{ koefisien } \\
\hline \multirow{2}{*}{\multicolumn{2}{|c|}{ Model }} & \multicolumn{2}{|c|}{$\begin{array}{l}\text { Koefisien tidak } \\
\text { standar }\end{array}$} & \multirow{2}{*}{$\begin{array}{c}\text { Koefisien } \\
\text { Standar } \\
\text { Beta }\end{array}$} & \multirow[b]{2}{*}{$\mathrm{T}$} & \multirow{2}{*}{$\begin{array}{c}\text { Tanda } \\
\text { tanga } \\
n\end{array}$} \\
\hline & & $\mathrm{B}$ & $\begin{array}{c}\text { Std. } \\
\text { Kesalahan }\end{array}$ & & & \\
\hline & (Konstan) & 16.502 & 5.057 & & 3.263 &, 002 \\
\hline & $\begin{array}{l}\text { Budaya } \\
\text { organisasi }\end{array}$ & , 189 & , 169 & ,134 & 1,121 & ,266 \\
\hline & Kepuasan kerja & 1,256 & 210 & ,713 & 5.970 &, 000 \\
\hline
\end{tabular}

\section{Uji Normalitas}

Uji normalitas dilakukan dengan tujuan untuk menguji apakah dalam suatu model regresi variabel terikat atau keduanya berdistribusi normal atau tidak (Umar, 2014).

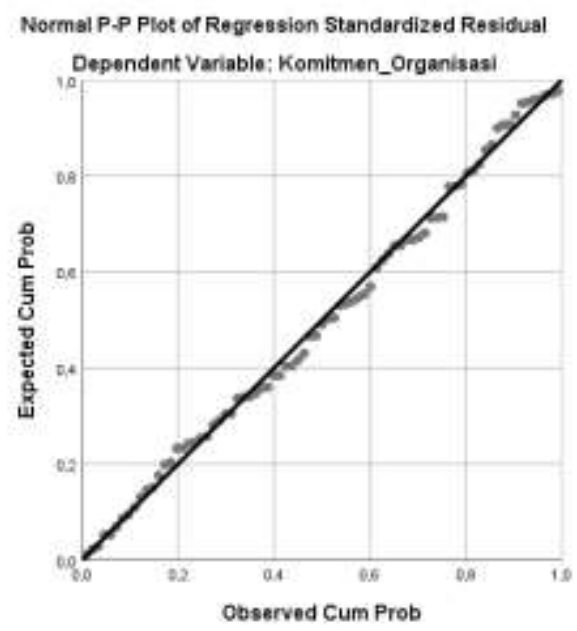

Gambar 1.1 Uji Normalitas

Berdasarkan gambar di atas terlihat bahwa titik-titik mendekati garis diagonal, dan distribusinya mengikuti garis diagonal, sehingga regresi ini dapat dikatakan normal.

Tabel 1.3 Uji Komogrorov-Smirnov. Hasil Uji Normalitas

\begin{tabular}{|l|r|r|}
\hline \multicolumn{2}{|c|}{ Tes Kolmogorov-Smirnov Satu Sampel } \\
\hline \multicolumn{2}{|c|}{} & Residual Tidak Standar \\
\hline $\mathrm{n}$ & & 79 \\
\hline Parameter Normal, b & berarti &, 0000000 \\
\hline
\end{tabular}




\begin{tabular}{|l|r|r|}
\hline & Std. Deviasi & 3.66258908 \\
\hline \multirow{4}{*}{ Perbedaan Paling Ekstrim } & .042 \\
\cline { 2 - 3 } & Mutlak & .042 \\
\cline { 2 - 3 } & Positif & -.042 \\
\cline { 2 - 3 } Statistik Uji & .042 \\
\hline asim. Tanda tangan (2-ekor) & $, 200 \mathrm{c}, \mathrm{d}$ \\
\hline sebuah. Distribusi tes Normal. \\
\hline B. Dihitung dari data. \\
\hline C. Koreksi Signifikansi Lilliefors. \\
\hline D. Ini adalah batas bawah dari arti sebenarnya. \\
\hline
\end{tabular}

Berdasarkan tabel di atas, dapat dilihat dari uji normalitas Kolmogorof-Smirnov berada pada Asymp. Sig (2-tailed) sebesar 0,200>0,05 yang berarti data tersebut normal.

\section{Tes T Uji}

Uji t dilakukan untuk menunjukkan apakah variabel independen berpengaruh signifikan terhadap variabel dependen. Hasil pengujian hipotesis penelitian dengan menggunakan uji-t adalah sebagai berikut:

Tabel 1.4 Hasil Uji Hipotesis Pertama

\begin{tabular}{|c|c|c|c|c|c|c|}
\hline \multicolumn{7}{|c|}{ koefisien } \\
\hline \multirow{2}{*}{\multicolumn{2}{|c|}{ Model }} & \multicolumn{2}{|c|}{$\begin{array}{l}\text { Koefisien tidak } \\
\text { standar }\end{array}$} & \multirow{2}{*}{$\begin{array}{c}\text { Koefisien } \\
\text { Standar } \\
\text { Beta }\end{array}$} & \multirow[b]{2}{*}{$\mathrm{T}$} & \multirow[b]{2}{*}{$\begin{array}{l}\text { Tanda } \\
\text { tangan }\end{array}$} \\
\hline & & $\mathrm{B}$ & $\begin{array}{c}\text { Std. } \\
\text { Kesalahan }\end{array}$ & & & \\
\hline & (Konstan) & 18.370 & 6.078 & & 3.023 &, 003 \\
\hline & $\begin{array}{l}\text { Budaya } \\
\text { organisasi }\end{array}$ & 1.037 & , 109 &, 735 & 9.502 & ,000 \\
\hline
\end{tabular}

Berdasarkan tabel di atas, dapat disimpulkan bahwa variabel budaya organisasi memiliki pengaruh terhadap komitmen organisasi. Hal ini dibuktikan dengan p-value $(\mathrm{Sig})<0,05$ yaitu $0,000<0,05$ dan nilai $t_{\text {hitung }}>t_{\text {tabel }}$. yaitu 9,502 $>1,664$ maka H0 ditolak dan Ha diterima. Sehingga dapat disimpulkan bahwa variabel budaya organisasi berpengaruh positif dan signifikan terhadap komitmen organisasi.

Tabel 1.5 Hasil Uji Hipotesis Kedua

\begin{tabular}{|c|c|c|c|c|c|}
\hline \multicolumn{6}{|c|}{ koefisien } \\
\hline \multirow[b]{2}{*}{ Model } & \multicolumn{2}{|c|}{$\begin{array}{l}\text { Koefisien tidak } \\
\text { standar }\end{array}$} & \multirow{2}{*}{$\begin{array}{c}\text { Koefisien } \\
\text { Standar } \\
\text { Beta }\end{array}$} & \multirow[b]{2}{*}{$\mathrm{T}$} & \multirow[b]{2}{*}{$\begin{array}{l}\text { Tanda } \\
\text { tangan }\end{array}$} \\
\hline & B & \begin{tabular}{|c} 
Std. \\
Kesalahan
\end{tabular} & & & \\
\hline \begin{tabular}{l|l}
1 & (Konstan) \\
\end{tabular} & 19.240 & 4,436 & & 4.337 &, 000 \\
\hline Kepuasan kerja & 1,454 &, 113 & ,826 & 12.836 &, 000 \\
\hline
\end{tabular}


Berdasarkan tabel di atas, dapat disimpulkan bahwa variabel budaya organisasi memiliki pengaruh terhadap komitmen organisasi. Hal ini dibuktikan dengan p-value $(\mathrm{Sig})<0,05$ yaitu $0,000<0,05$ dan nilai $t_{\text {hitung }}>t_{\text {tabel }}$.yaitu $12.836>1.664$ maka H0 ditolak dan Ha diterima Sehingga dapat disimpulkan bahwa variabel kepuasan kerja berpengaruh positif dan signifikan terhadap komitmen organisasi.

\section{Tes F Uji}

Uji $\mathrm{F}$ bertujuan untuk mengetahui pengaruh variabel independen secara bersama-sama terhadap variabel dependen yaitu variabel Budaya Organisasi (X1) dan Kepuasan Kerja (X2) secara bersama-sama terhadap Komitmen Organisasi (Y). Berikut hipotesis ketiga yang diajukan dalam penelitian ini, yaitu:

Tabel 1.6 Hasil Uji Hipotesis Ketiga

\begin{tabular}{|c|c|c|c|c|c|c|}
\hline \multicolumn{7}{|c|}{ ANOVA } \\
\hline \multicolumn{2}{|c|}{ Model } & Jumlah Kuadrat & df & $\begin{array}{c}\text { Rata-rata } \\
\text { Persegi }\end{array}$ & $\mathrm{F}$ & $\begin{array}{l}\text { Tanda } \\
\text { tangan }\end{array}$ \\
\hline & Regresi & 2293.209 & 2 & 1146.604 & 83.283 &, $000 \mathrm{~b}$ \\
\hline & Sisa & 1046,336 & 76 & 13.768 & & \\
\hline & Total & 3339.544 & 78 & & & \\
\hline
\end{tabular}

Berdasarkan hasil tabel di atas dapat diketahui bahwa budaya organisasi dan kepuasan kerja berpengaruh signifikan terhadap komitmen organisasi. Hal ini dapat dibuktikan dengan nilai p-value (Sig) $<0,05$ yaitu 0,000 dan nilai Fhitung $>$ Ftabel yaitu $83,283>3,12$ yang berarti bahwa variabel budaya organisasi dan kepuasan kerja secara bersama-sama mempunyai pengaruh yang positif dan signifikan. pada komitmen organisasi.

\section{KESIMPULAN}

Budaya Organisasi berpengaruh positif dan signifikan terhadap Komitmen Organisasi. Artinya semakin kuat budaya organisasi dalam perusahaan maka akan semakin meningkat pula komitmen organisasional karyawan di dalam perusahaan. Kepuasan Kerja berpengaruh positif dan signifikan terhadap Komitmen Organisasi. Artinya semakin tinggi kepuasan kerja yang dirasakan pada karyawan maka akan berdampak pada peningkatan komitmen karyawan pada organisasi atau perusahaan.

Budaya Organisasi dan Kepuasan Kerja secara simultan berpengaruh positif dan signifikan terhadap komitmen organisasi. Artinya budaya organisasi dan kepuasan kerja yang ada di perusahaan dan tone karyawan akan berdampak pada peningkatan loyalitas karyawan atau komitmen karyawan terhadap karyawan.

\section{DAFTAR PUSTAKA}

Al-sada, M. (2017). Pengaruh budaya organisasi dan gaya kepemimpinan terhadap kepuasan, komitmen dan motivasi. Wawasan Zamrud, 4.

Busro, M. (2018). Teori Manajemen Sumber Daya Manusia. Prenadamedia Group. Edison, E., Anwar, Y., \& Komariyah, I. (2018). Manajemen Sumber Daya Manusia. Alfabeta. 
Ghozali, I. (2016). Aplikasi Analisis Multivariat dengan Program IBM SPSS 21. Badan Penerbit Universitas Diponegoro.

Kaswan. (2015). Sikap Kerja: Dari Teori dan Implementasi Untuk Bukti. Alfabeta. Siagian, S. P. (2006). Manajemen Sumber Daya Manusia. Bumi Aksara.

Sugiyono. (2017). Metode Penelitian Kuantitatif, Kualitatif, dan R\&D. Alfabeta.

Umar, H. (2014). Metode Penelitian Untuk Skripsi dan Tesis Bisnis. Rajawali Pers.

Wibowo. (2019). Perilaku dalam Organisasi. PT Rajagrafindo Persada.

Yuwalliatin, S. (2006). Pengaruh Budaya Organisasi, Motivasi, dan Komitmen

Terhadap Kinerja Serta Pengaruhnya Terhadap Keunggulan Kompetitif. EKOBIS, 7. 